\title{
Leaf area index change in ice-storm-damaged sugar maple stands ${ }^{1}$
}

\author{
by Ian Olthof ${ }^{2}$, Douglas J. King ${ }^{2}$ and R.A. Lautenschlager ${ }^{3}$
}

\begin{abstract}
Changes in Leaf Area Index (LAI) between the summers of 1999 and 2000 were measured using the TRAC optical instrument in sugar maple stands damaged by the 1998 ice storm. Changes were determined to be significant if they were greater than the $95 \%$ bounds of the instrument precision. They were evaluated in relation to 1998 canopy damage estimates, 1999 stand treatments (lime, fertilizer, lime + fertilizer, herbicide, none), and 1999 understory vegetation cover. Results show that LAI change is significantly related to overstory damage, and understory abundance in the $0-7-\mathrm{m}$ height range. Plot treatments were not related to these LAI changes, possibly due to the short time interval between application and LAI measurement.
\end{abstract}

Keywords: forest damage, ice storm, leaf area index, optical instruments, TRAC

Les changements au niveau de l'indice de surface foliaire (ISF) entre l'été 1999 et l'été 2000 ont été mesurés au moyen de l'instrument optique TRAC dans des peuplements d'érable à sucre endommagés par la tempête de verglas de 1998. Les changements ont été identifiés comme étant significatifs s'ils étaient supérieurs à la limite de $95 \%$ liée à la précision de l'appareil. Les changements ont été évalués en fonction des estimés des dégâts au couvert forestier de 1998, des traitements effectués dans les peuplements en 1999 (chaux, fertilisants, chaux et fertilisants, phytocide, aucun traitement), et du couvert végétal du sous-bois en 1999. Les résultats indiquent que les changements de l'ISF sont reliés de façon significative aux dégâts de la voûte arborescente, et de l'importance du sous-étage entre 0 et $7 \mathrm{~m}$ de hauteur. Les parcelles traitées ne sont pas reliées à ces changements d'ISF, probablement suite au court intervalle entre le moment de l'application et la mesure de l'ISF.

Mots-clés: dégât forestier, verglas, indice de surface foliaire, instruments optiques, TRAC

\section{Entroduction}

ธี The 1998 ice storm that struck Eastern North America was 品 unprecedented weather event in recent North American histry. Freezing rain was deposited over much of Eastern North fimerica, from Eastern Ontario through to the Maritimes, and far south as northern New York and New England. In the Worst hit areas, precipitation exceeded $100 \mathrm{~mm}$, representing Eifinore than double the amount of previous severe ice storm events (Environment Canada 1998). Due to the unparalleled scale and magnitude of the event (Lautenschlager and Nielsen 1999), its Oimpacts were entirely unforeseeable.

Based on the 1998 ice storm experience, it is evident that a better understanding is required of both spatial and temporal effects of natural disturbances on forests. Monitoring needs include Uaccurate characterization of damage in the field and consistent and repeatable measurements of forest response to damage through s time. Methods must also be developed to extrapolate, or o "scale," this information across the affected area to aid in optimal allocation of resources for cleanup and recovery.

Temporal monitoring requires precise, repeatable measurement of forest parameters in the field to assess response to damage. Visual estimation of crown loss is widely used as an initial measure of damage. While visual estimates have been found to be as accurate as individual or repeated PAR mea-

\footnotetext{
'Paper presented at the Ice Storm 1998 Forest Research Conference, Ottawa, October 19-22, 2000.

${ }^{2}$ Carleton University, Department of Geography and Environmental Studies, Ottawa, ON K1S 5B6. E-mail: iolthof@ccs.carleton.ca, doug_king@ carleton.ca.

${ }^{3}$ Ontario Ministry of Natural Resources, Ontario Forest Research Institute, 1235 Queen Street East, Sault Ste. Marie, ON P6A 2E5. E-mail: r.a.lautenschlager@mnr.gov.on.ca.
}

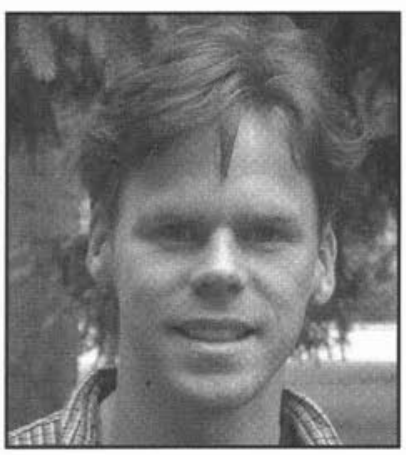

Ian Olthof

surements for estimating nearground cover (Ter-Mikaelian et al. 1999) and they provide useful qualitative information on crown damage, instrumentbased measurement may be used in a complementary fashion to validate visual estimates and to provide additional forest structure information. Conceptually, instrument-based measurement should also provide more objective, repeatable and precise measurement than visual estimates, because bias over time for a given assessor or among assessors is not present as long as instrument calibration and use remain constant.

In this study, the instrument that was selected to monitor plotbased structural response to ice storm damage was the TRAC 
(Tracing Radiation and Architecture of Canopies), an optical instrument developed at the Canada Centre for Remote Sensing (Chen and Cihlar 1995). It provides detailed spatial sampling of sunflecks that is used to calculate the canopy gap fraction, the degree of randomness of canopy gaps, and leaf area index (LAI).

Leaf Area Index is defined as one half the total leaf area per unit area on the ground (Chen and Black 1992). It is an important biophysical parameter for estimating gas and energy exchanges with the atmosphere (Norman 1993). It also affects primary productivity and is therefore critical to climate by influencing the amount of carbon that can be sequestered by a vegetated surface. LAI is also an important structural parameter for characterizing canopy architecture and it is affected by mechanical damage caused by disturbance. LAI has been used to characterize forest damage due to contamination and high winds at an abandoned mine site (Olthof and King 2000), and ice storm damage in unmanaged maple stands (Pellikka et al. 2000).

Methods for estimating LAI are classified as direct or indirect (Chen et al. 1997a). Direct methods involve destructive sampling, litter fall collection or point sampling, and rely on the development of allometric equations relating LAI to basal area for extrapolation. Indirect methods involve the measurement of light transmitted through the canopy with optical instruments and either physical or statistical models relating optical measures to LAI. Direct methods have been used successfully in agriculture (Welles and Norman 1991), but are generally not practical in forests due to the labour required to fell and sample trees. In addition, allometric equations relating LAI to basal area cannot be directly applied to damaged trees, since LAI depends not only on basal area, but also on the degree of damage sustained. For these reasons, indirect measures of LAI are preferred when attempting to assess the response of a forest to damage.

Of several instruments for indirect measurement of LAI, the two most common are hemispherical photographs (Welles 1990) and the LiCor LAI-2000 Plant Canopy Analyzer (Li-Cor 19991). Both can be used to calculate the gap fraction at multiple view angles and both assume a random distribution of gap sizes, leaves and leaf orientations in estimating LAI. These assumptions of randomness are not valid in forests where leaves are "clumped" into shoots, and shoots into trees. Consequently, forest LAI determined with such instruments often significantly underestimates actual LAI (Welles and Cohen 1996). In the literature, these LAI estimates are often termed "effective LAI,"

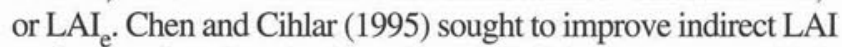
estimates by developing the TRAC instrument, which determines the gap size distribution and calculates the degree of clumping of foliage elements as a continuous measure between 1 (random) and 0 (non-random). This clumping index is divided into the effective LAI, providing greater absolute accuracy than the LAI-2000 or hemispheric photographs (note that these instruments are quite useful for relative measurements of LAI). More detailed discussion of the TRAC operation is provided later in this paper.

The TRAC instrument was selected for LAI measurement in this study because it provides reliable estimates of LAI in forests with non-random (i.e., clumped) leaf elements. Accounting for foliage clumping may be especially important when measuring LAI in damaged forests, since clumping is suspected to be more pronounced where entire branches are broken, leaving large gaps in the canopy adjacent to intact or slightly damaged branches.

\section{Forest ice storm damage}

Interactions among climate, site and tree form affect susceptibility to damage by ice loading on branches. Physiographic, geographic and weather system factors affect the distribution and intensity of precipitation, resulting in patchy damage across the landscape. Tree form, including factors such as crown size, branch angle and structure, affects the amount of damage that may be sustained, and is dependent upon species, age and site (Irland 1998, Van Dyke 1999). Thus, ice storm damage commonly varies by species and site.

Overall crown surface area and form play a role in accumulation; trees with finer branching structure have greater surface area for ice accumulation per tree volume than trees with coarser branches. Older trees tend to be more prone to breakage due to increased crown size, superior crown position, less flexible branches than younger trees, and predisposition to decay and disease. The horizontal and opposite branching structure of decurrent forms (branching with larger angles) tends to accumulate heavier ice loads. Trees in the upper canopy suffer most due to exposure and crown size (Hauer et al. 1994, Van Dyke 1999). Given the factors that affect an individual tree's susceptibility to damage, stand structures that produce highly susceptible forms will result in more damage by ice loading.

Damage assessment may be conducted at a range of scales from the individual leaf to the entire stand (Mageau et al. 1995). Indicators at the individual leaf or branch levels typically include measures of plant physiological stress using direct (e.g., leaf chemistry) or indirect (e.g., chlorophyll fluorescence) methods (Sampson et al.2000). At the tree scale, indicators measure structural or crown productivity parameters such as percentage crown loss, decrease in crown closure, branches remaining (Lautenschlager and Winters 2001) or foliar biomass (Ter-Mikaelian and Lautenschlager 2001). These are often aggregated over several samples to form an area- (plot-) based measure. In this study, measurement of LAI integrates both canopy and individual crown structure as gaps and foliage are measured based on sunflecks and shadows encountered along transects in forest plots. LAI is compared to percentage crown loss aggregated from sample trees in the plot.

\section{Objectives}

The primary objective was to determine if Leaf Area Index (LAI) had changed significantly in sample sugar maple stands in southeastern Ontario between the summers of 1999 and 2000. These stands had suffered various levels of damage and had been treated with lime, fertilizer, herbicide, or left untreated in a plotbased experimental design (Lautenschlager and Nielsen 1999).

In order to meet this objective, repeat measurements of LAI were made within plots in 1999 and 2000. To determine if differences in LAI measurements for a given plot were significant over this one-year period, an analysis of the precision of the TRAC instrument was conducted using repeat measures taken within short periods of time during which LAI was not expected to change. The $95 \%$ bounds of the distribution of differences from these precision repetitions were taken to represent the noise of the measurement technique (instrument + operational variation), as LAI should not have changed. Therefore, 


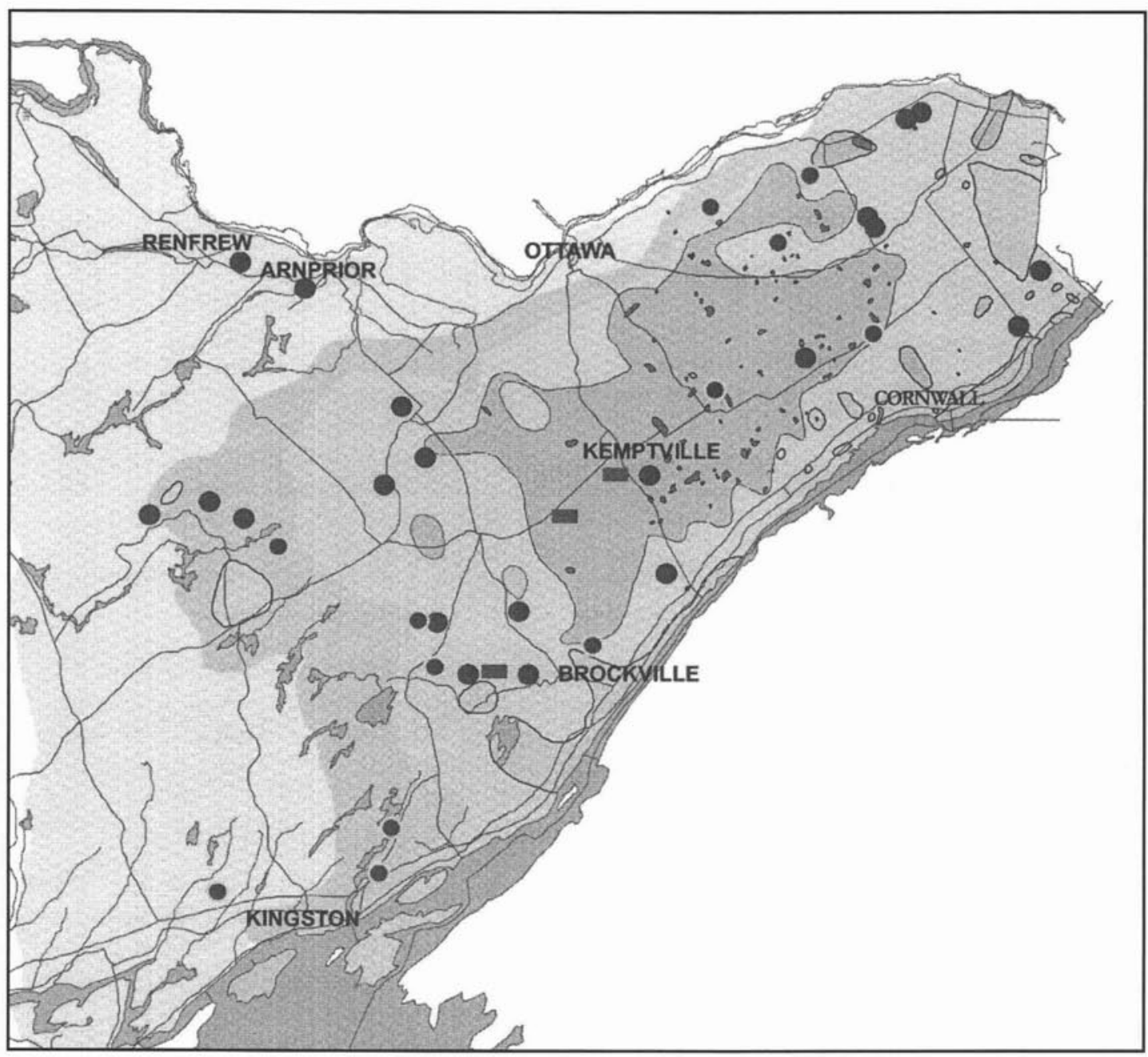

Fig. 1. Block placement (circles and rectangles) in productive sugar bushes across southeastern Ontario, superimposed on ice damage map for that area [damage severity increases with background shading - light, moderate, moderate to severe (central dark ameboid shape), severe].

1999-2000 differences that exceeded the $95 \%$ precision bounds (the noise) of the instrument were deemed to be statistically significant and were investigated against plot treatment, damage and understory abundance using statistical analysis.

\section{LAI measurement using the TRAC}

The TRAC optical instrument consists of a LiCor Inc. Quantum sensor affixed to a wand that encloses a data storage unit (Fig. 2). The instrument acquires constant light readings in the $400-700-\mathrm{nm}$ (visible light) range at a rate of 32 measurements per second. A button on the handle of the instrument is depressed to start and stop the instrument recording, and to insert time stamps at distance intervals in the data.

Transects are set up in the forest within 20 degrees of perpendicular to the sun's azimuth during measurement (the illumination direction), with markings or flags at pre-determined intervals. The operator holds the instrument at a constant height of approximately $1.5 \mathrm{~m}$ above the ground and walks along a transect at a steady pace of about $1 \mathrm{~m}$ every three seconds. Time is stamped into the data file at each flag so that the light measurements may be registered to known distance in the forest. The data are downloaded to a computer for subsequent analysis. They consist of photon flux density measurements in micromoles per metre squared per second $\left(\mu \mathrm{mol} \mathrm{m}^{-2}\right.$ $\mathrm{s}^{-1}$ ) of sunlight penetrating the canopy at the solar zenith angle (SZA) during measurement. Note that this mechanism of measuring sunflecks and shadows falling on the sensor as a transect is traversed is quite different from the cumulative angle measurements of portions of the sky taken at fixed points with the LiCor LAI-2000, or hemispherical photography. The TRAC is also operated under clear sky conditions, while the other two instruments are operated under diffuse illumination (dawn/dusk or uniform cloud).

The data represent a profile of radiance measured beneath the forest canopy. Sunflecks along the profile, where the sensor is illuminated by the sun, represent canopy gaps in the direction of the sun (i.e., not vertically) at the time of measurement. The accompanying software determines where gaps occur along the transect by measuring the rate of change of photon flux along the profile. The distance between a sharp increase in irradiance followed by a subsequent decrease represents the gap size along one axis. The cumulative gap size distribution is then determined as the total proportion of gaps smaller than a given gap size (Chen and Cihlar 1995). Gap size distribution, mean element width of leaves (input by the user) and solar zenith angle (determined by transect location and time of data acquisition) are then used to calculate total gap fraction, clumping index, and LAI.

The optical theory for the TRAC is given in Chen and Cihlar (1995). The instrument has been successfully tested in 
Table 1. Plot treatments for sugar maple ice damage study in Eastern Ontario

\begin{tabular}{ll}
\hline Treatment $\quad$ Fertilizer / herbicide application \\
\hline A & no treatment \\
B & $500 \mathrm{~kg}$ Dolomitic lime $+50 \mathrm{~kg}$ phosphorus $+50 \mathrm{~kg}$ potassium \\
C & $50 \mathrm{~kg}$ phosphorus $+50 \mathrm{~kg}$ potassium \\
D & $500 \mathrm{~kg}$ Dolomitic lime \\
& \multicolumn{1}{c}{ Herbicide Blocks, $n=3$} \\
A & no treatment $\quad 500 \mathrm{~kg}$ Dolomitic lime $+50 \mathrm{~kg}$ phosphorus $+50 \mathrm{~kg}$ potassium and \\
B & herbicide $\left(\right.$ Vision $\left.^{\otimes}\right)$ control \\
C & $500 \mathrm{~kg}$ Dolomitic lime $+50 \mathrm{~kg}$ phosphorus $+50 \mathrm{~kg}$ potassium \\
D & Herbicide treatment $($ Vision
\end{tabular}

coniferous forests (Chen and Cihlar 1995, Chen 1996, Chen et al. 1997a) and healthy deciduous forests (Chen et al. 1997a, b). Chen and Cihlar (1995) obtained LAI estimates to within 9\% in pine plantations. Chen et al. (1997a) also obtained good agreement between allometric and TRAC LAI measurements in boreal coniferous and deciduous stands. To-date, detailed comparisons of the TRAC to the LAI-2000, hemispheric photographs or other optical instruments for deciduous forest LAI measurement have not been published; however, this is part of our ongoing research at Carleton University.

LAI measurement using the TRAC in structurally damaged forests has also not been previously reported. Two important differences between previous applications and this study are the expected higher degree of foliage clumping and increased vertical structure due to sub canopy and understory response to increased light levels in damaged forests (Sipe et al. 1994).

\section{Methods}

In order to address the economic and ecological concerns of maple syrup producers in Eastern Ontario, the Ontario Ministry of Natural Resources (OMNR) established 38 treatment blocks in a variety of management, site and damage classes in sugar maple bushes across Eastern Ontario (Fig. 1) (Lautenschlager and Nielsen 1999). Each block is square, $100 \mathrm{~m}$ on a side and is divided into four $50 \mathrm{~m} \times 50 \mathrm{~m}$ plots consisting of one control and three fertilizer or herbicide / fertilizer treatments randomly assigned to plots and applied in the spring of 1999 (Table 1).

\section{LAI measurement}

Three 50-m transects were installed in individual plots in an east-west direction for LAI measurement. Transects were spaced $10 \mathrm{~m}$ apart, and were always located in the northern portion of the plot to ensure that radiation incident upon the instrument was passing through the canopy in the plot (as the sun zenith was always at approximately $40^{\circ}$ during measurement). The transects consisted of metal flags placed at ten metre intervals. An operational strategy for transect installation and measurement had to be developed because the blocks were located across Eastern Ontario and measurement had to be performed under clear sky conditions. They were typically set up in a given plot before the day of measurement when the sky was cloudy or in the early or late part of the day. This allowed measurements to be taken during a cloud-free or partly cloudy period between $11 \mathrm{AM}$ and $3 \mathrm{PM}$ ( \pm 2 hours of solar noon) when the sun was within 20 degrees of perpendicularity to the transect. This is considered an acceptable range of solar angle variation for consistent LAI measurement (Chen, J., 1998, personal communication), although it is expected that some variability is introduced. An assistant walked ahead of the operator to clear any obstructions that would have impeded a steady pace. All measurements were taken on clear days to ensure that the boundaries between sunflecks and shadows were sharp for consistent gap detection and measurement. In calculating LAI, a mean leaf element width for sugar maple of $85 \mathrm{~mm}$ was used (Chen, J., 1998, personal communication).

\section{Forest damage and structure}

The OMNR provided both block- and plot-based damage measures acquired in the fall of 1998 . The first was canopy damage based on visual estimates in the blocks. The second was the percentage of crown loss on an individual tree basis estimated for six focus trees per plot. The individual tree crown loss data, averaged over the entire block ( $\mathrm{N}=24$ per block) correlated well with the block-based damage estimates $(r=0.93$, $\mathrm{N}=34$ blocks), indicating consistency between these two damage measures. Individual tree estimates of crown loss were unavailable for 1998 in 4 blocks, including one of the LAI change blocks (block 44). In subsequent plot-based analysis, the average per cent crown loss of the six focus trees was used as the primary damage measure.

\section{Ground vegetation survey}

Near-ground vegetation survey data were collected by the OMNR from July 15 to September 20, 1999 in the second growing season after the ice storm and before effects of the herbicide treatments could bias results. A line intercept method (Canfield 1941) was used to acquire vegetation data along five randomly located transects in each plot of each block.

Vegetation was recorded by species and layers as well as the start-end distance in centimetres on the 10-m line. All species less than $7 \mathrm{~m}$ in height with green or mostly green vegetation that crossed the line (projected vertically) were recorded. A metre stick and a height pole were used to determine vegetation heights (layers). Layers were recorded as: $0.0-0.5 \mathrm{~m}, 0.5 \mathrm{~m}-2.0 \mathrm{~m}$ and $2.0 \mathrm{~m}-7.0 \mathrm{~m}$. Three additional layer classes were added for species that occurred continuously in more than one of the previous layers. They included layers 1 and 2 combined $(0.0-2.0 \mathrm{~m})$, layers 2 and 3 combined $(0.5-7.0 \mathrm{~m})$ and all layers combined $(0.0-7.0 \mathrm{~m})$. Total abundance of understory vegetation $(0.0-7.0 \mathrm{~m})$ was calculated by summing the distance in centimetres of Layers 1-6 on a plot-by-plot basis.

\section{Assessment of LAI change}

To assess differences in structure between seasons, 32 plots that were measured in 1999 were re-measured in the summer of 2000. Every effort was made to re-measure plots as close as possible to the same day both years. Most paired measurements were done within two weeks of each other in the growing season. However, measurements on 12 plots were done within two months of each other (August 15, 1999 and June 10, 2000). The large separation in anniversary dates for these 12 plots was due to operational factors such as block separation distances and weather. As these are typical operational constraints in such studies, and as LAI does not change significantly in northern deciduous forests between June and August (Chen et al.1997b) 


\begin{tabular}{lccccccc}
\hline & & & & & \multicolumn{2}{c}{ 95\% confidence interval } \\
\cline { 5 - 8 } & Range & Minimum & Maximum & Mean & Std. D. & Lower limit & Upper limit \\
\hline 112 & 2.66 & -1.33 & 1.33 & 0 & 0.61 & -1.20 & 1.20 \\
\hline
\end{tabular}

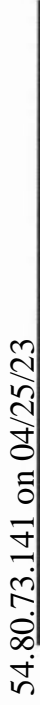

these data were deemed acceptable for the analysis. The sign on of the LAI differences $\left(\mathrm{LAI}_{2000}-\mathrm{LAI}_{1999}\right)$ indicated the direction of change, as either an increase in LAI in the case of Fositive change or a decrease in the case of negative change. O All measured LAI change in these plots could not be assumed to be real change since the TRAC instrument and sun

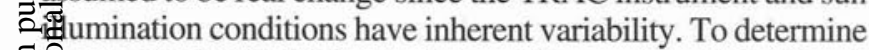
g the magnitude of LAI change that could be considered significant, De precision of the instrument was determined through repeatIf measurements within the same growing season. Either Itwo or three within-season repeat measurements were taken in 29 plots. Eighteen of the 29 plots had repeat measurements taken on the same day at different times. The other plots had repeat measurements taken over a span of several days. The largest time span between repeat measurements was 48 days between July 5, 2000 and August 22, 2000. The precision analysis twas designed to emulate operational conditions (and the conditions of the LAI change analysis) where measurements between seasons may not be possible within close anniversary ơd dates.

Precision analysis was conducted by examining paired differences between the repeat measurements. Paired differences were calculated by subtracting the first measurement from the second and then the second from the first. In plots where only two measurements were taken, two paired differences were considered. In cases where three measurements were taken, six paired differences of all possible pairs were considered. By treating paired differences in this fashion, their distribution was perfectly symmetrical (unskewed) with a mean of zero. The paired LAI differences of these within season repeat measurements formed a normal probability distribution (based on tests of kurtosis). The 1999-2000 LAI differences were then compared with this within season paired difference distribution. All 1999-2000 LAI measurements that fell between the $95 \%$ bounds of the within season distribution were deemed to be too small to be significant, as they could not be distinguished from instrument vari-

\begin{tabular}{lccccc}
\hline \multicolumn{6}{c}{ Table 3. Descriptive } \\
\hline & N & Minimum & Maximum & Mean & Std. Deviation \\
\hline 1999 LAI & 32.00 & 2.87 & 6.67 & 4.44 & 0.91 \\
2000 LAI & 32.00 & 3.80 & 6.22 & 5.32 & 0.72 \\
\hline
\end{tabular}

ability. The 1999-2000 LAI differences greater than the $95 \%$ bounds of this distribution were deemed to be significant and beyond what the instrument would produce through inherent and operational noise.

\section{Factors related to LAI change}

An analysis of factors potentially related to LAI change was then conducted. A two-way analysis of variance (ANOVA) was used to determine if change in LAI was dependent on plot treatment, with blocks as replicates in a randomized design (Snedecor and Cochran 1980). Assumptions that form the basis of ANOVA include normality of observations on the dependent variable within each group and homogeneity of variance (equal population variances) between groups. Group sizes were constant at eight plots per treatment and four treatments per block. Therefore, neither within-group variance nor normality were considered to significantly affect the actual type I error rate (Stevens 1992). Correlation analysis was used to examine association of damage estimates and ground vegetation abundance with change in LAI. For plots where repeat measurements had been taken in a single year, LAI for that year was taken as the average of the repeats.

\section{Results and Discussion}

Single date measurements of LAI and clumping index were significantly related to damage. More highly damaged plots had lower $\mathrm{LAI}(\mathrm{R}=-0.444, \mathrm{P}<0.01)$ and a higher degree of clumping $(\mathrm{R}=-0.203, \mathrm{P}<0.05)$, as expected. Thus, LAI may be an appropriate surrogate measure for monitoring forest response 


\begin{tabular}{|c|c|c|c|c|c|c|c|c|}
\hline \multirow[b]{2}{*}{ Block } & \multicolumn{2}{|c|}{ Treatment A } & \multicolumn{2}{|c|}{ Treatment B } & \multicolumn{2}{|c|}{ Treatment C } & \multicolumn{2}{|c|}{ Treatment D } \\
\hline & $\begin{array}{c}\text { LAI } \\
\text { change* }\end{array}$ & $\begin{array}{c}\% \\
\text { difference* }\end{array}$ & $\begin{array}{c}\text { LAI } \\
\text { change* }\end{array}$ & $\begin{array}{c}\% \\
\text { difference* }\end{array}$ & $\begin{array}{c}\text { LAI } \\
\text { change* }\end{array}$ & $\begin{array}{c}\% \\
\text { difference* }\end{array}$ & $\begin{array}{c}\text { LAI } \\
\text { change* }^{*}\end{array}$ & $\begin{array}{c}\% \\
\text { difference }\end{array}$ \\
\hline 3 & 1.075 & $30.40 \%$ & 0.31 & $8.10 \%$ & 0.96 & $23.40 \%$ & 1.44 & $34.80 \%$ \\
\hline 9 & 1.38 & $30.50 \%$ & 1.5 & $36.00 \%$ & 1.76 & $43.90 \%$ & 1.12 & $25.10 \%$ \\
\hline 30 & 0.33 & $7.50 \%$ & 1.41 & $29.60 \%$ & 1.2 & $24.60 \%$ & 0.98 & $21.40 \%$ \\
\hline 31 & 0.45 & $8.30 \%$ & 0.5 & $9.00 \%$ & 0.67 & $13.80 \%$ & 1.29 & $26.50 \%$ \\
\hline 40 & -0.28 & $-4.80 \%$ & -0.49 & $-7.30 \%$ & 0 & $0.00 \%$ & -0.27 & $-4.50 \%$ \\
\hline 42- herbicide & 1.59 & $43.80 \%$ & 0.99 & $24.80 \%$ & 1.02 & $25.00 \%$ & 0.93 & $32.40 \%$ \\
\hline 43-herbicide & 1.46 & $37.60 \%$ & 1.47 & $41.60 \%$ & 1.55 & $35.50 \%$ & 0.69 & $21.90 \%$ \\
\hline 44-herbicide & 0.78 & $18.20 \%$ & 0.85 & $23.80 \%$ & 1.03 & $22.70 \%$ & 0.57 & $17.50 \%$ \\
\hline
\end{tabular}

*bold indicates change is significant beyond $95 \%$ precision confidence interval.

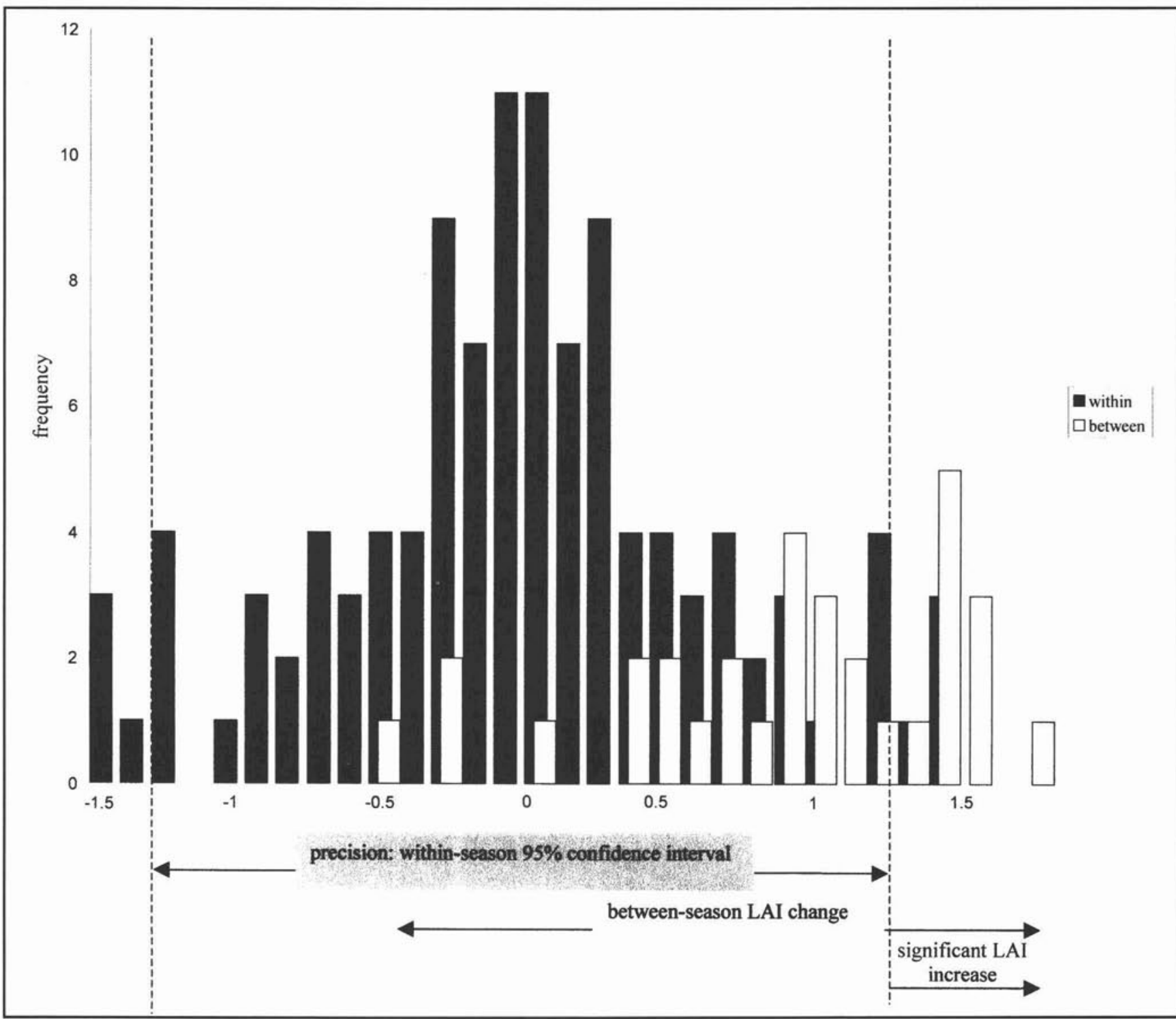

Fig. 3. Within and between season LAI measurement differences

to damage. While the strength of the relation between clumping and damage was quite low, it justified the appropriateness of use of the TRAC instrument in damaged forests over other optical methods that do not account for clumping in LAI measurement. This relation may be due to the damage itself, producing large gaps and therefore clumped foliage elements as was hypothesized earlier. The relation may also be due to differential susceptibility of stands to damage, with more open stands being more prone to ice loading and breakage. The latter hypothesis is supported in the literature relating stand structure to ice storm damage susceptibility (Hauer et al. 1994, Irland 1998, Van Dyke 1999). 


\begin{tabular}{lrcccc}
\hline \multicolumn{6}{l}{ Table 5. Two-way ANOVA of LAI change by block and treatment } \\
\hline $\begin{array}{l}\text { Source of } \\
\text { variation }\end{array}$ & df & $\begin{array}{c}\text { Sum of } \\
\text { squares }\end{array}$ & $\begin{array}{c}\text { Mean } \\
\text { square }\end{array}$ & F & Sig. \\
\hline BLOCK & 7 & 7.55 & 1.08 & 8.20 & 0.00 \\
TREATMENT & 3 & 0.21 & 0.07 & 0.54 & 0.66 \\
Residual & 21 & 2.76 & 0.13 & & \\
Total & 31 & 10.53 & 0.34 & & \\
\hline
\end{tabular}

Table 6. Correlation matrix between LAI change and forest structure

\begin{tabular}{lcc}
\hline & Damage & Understory \\
\hline LAI change & 0.384 & 0.315 \\
Significance $(\mathrm{P})$ & 0.044 & 0.079 \\
\hline
\end{tabular}

\section{LAI measurement precision}

$\widehat{N}$ From repeat within-season LAI measurements, the LAI Sprecision distribution of paired differences was plotted. NorOmality of the distribution was assessed, revealing slightly Olong-tails, which was corrected by eliminating a single outliFer. It is suspected that the outlier had an extreme difference between repeats due to incoming clouds during data acquisition. The $95 \%$ Confidence limits for LAI precision were determined as \pm 1.20 \&. Table 2). It was verified that 104 of 112 (93\%) repeat differinences were within the calculated $95 \%$ confidence limits of the zolistribution. LAI measurement differences greater than 1.20 between consecutive years were interpreted as having changed significantly between seasons (Fig. 2). The wide confidence Timerval is due primarily to variations in sun zenith and azimuth Jdoring the measurement periods. This variation was not a separation in dates of some repeat measurements a within day repeats exhibited greater variance than between Edo.

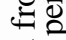

\section{gial I change}

Descriptive statistics of LAI for 32 plots measured in 1999 Fand again in 2000 are shown for individual years in Table 3.
Average LAI for these plots rose from 4.44 in 1999 to 5.32 in 2000. LAI increased in 28 of the 32 plots between 1999 and 2000 . Increases were determined to be significant $(>1.20)$ in 10 of the 32 plots, or $31 \%$ of the plots measured (Table 4). Of the twelve plots measured with widely separated anniversary dates (typically August of 1999 and late June of 2000), five showed significant LAI increases and seven did not. Excluding these plots from the analysis and considering only the 20 plots that were measured in both years with a separation of less than two weeks showed that five had significant LAI increases and a sixth was very close to being significant $($ LAI increase $=1.20$ ) (Fig. 3). Thus, approximately the same proportion of plots increased in LAI whether considering the full data set (31\% of plots significant) or the subset of 20 measured on essentially the same date in 1999 and 2000 (25-30\% of plots significant). Changes in LAI throughout the growing season are less than the instrument and operation variability and did not significantly affect this analysis.

ANOVA results revealed no significant differences in LAI change among treatments (Table 5), but that significant differences existed among blocks. Other TRAC parameters (clumping index, gap fraction) exhibited similar changes between years as LAI.

Correlation analysis was performed to determine if changes in LAI were linked to other forest structure parameters (Table 6). The analysis revealed that 1999-2000 increases in LAI were related to the level of damage in the plot at $\mathrm{P}<0.05$. Thus, higher damaged plots have generally exhibited greater increases in LAI than less damaged plots.

A scatterplot of LAI change versus damage illustrates this relation (Fig. 4). Block 31 appeared as an outlier, exhibiting high LAI increment in spite of suffering little ice storm damage. Blocks 31,42 and 43 (herbicide) had relatively little understory vegetation below $7.0 \mathrm{~m}$ in height after spraying and therefore measured increases in LAI in these blocks must have been due to growth in the canopy above $7.0 \mathrm{~m}$. LAI change was related to understory abundance at $\mathrm{P}<0.1$, suggesting that for nonherbicide-treated plots, some of the measured increases in

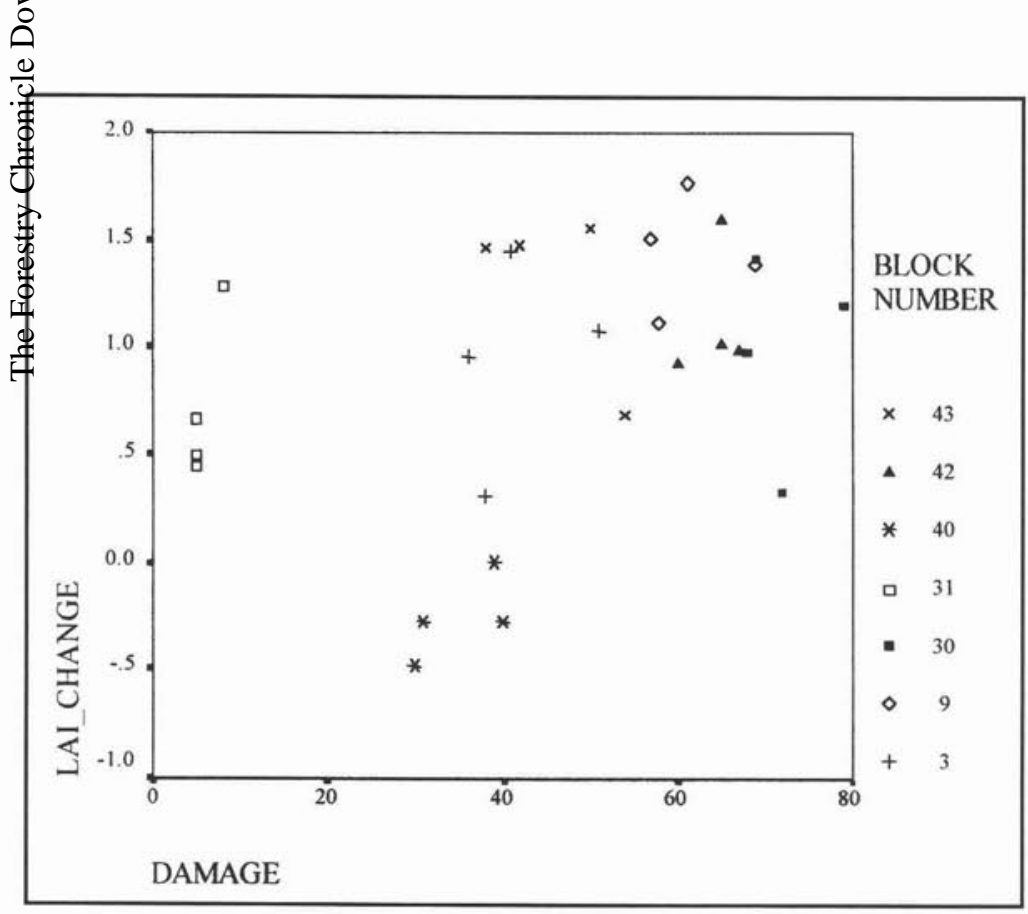

Fig. 4. Plot of damage versus LAI increment $(R=0.384$, $\mathrm{P}<0.05)$. 
leaf area were from understory vegetation layers. Although somewhat speculative, these results indicate that canopy trees in plots of low understory competition may increase in leaf area more than canopy trees in stands with significant understory vegetation. Further research will be conducted to evaluate this hypothesis.

This study demonstrates the usefulness of LAI for temporal monitoring of forest response to damage. Percentage crown loss as a measure of damage is useful to establish a baseline from which the response can be assessed, but may not provide the best measure for monitoring. Damage may become obscured from the ground in a few years time, and original crown volume becomes difficult to assess after new growth has occurred. Through LAI measurement with the TRAC, significant between season changes are discernible from instrument and operational variability, enabling temporal monitoring of LAI as the forest responds to damage.

\section{Conclusions}

LAI was measured with the TRAC optical instrument in 32 plots across Eastern Ontario in 1999 and 2000. These plots were part of experimental blocks, consisting of four treatments of lime, fertilizer, lime+fertilizer, herbicide and non-treated plots. Within-season repeat measurements were made in a subset of plots to assess measurement precision and determine the magnitude of between year LAI change that could be considered to be statistically significant. Plots in which LAI changed from 1999 to 2000 by an amount greater than the $95 \%$ confidence interval of the precision distribution (i.e., LAI changes of greater than 1.20) were deemed to be statistically significant and beyond the inherent noise range of the measurement technique and TRAC instrument. Almost $1 / 3$ of the measured plots increased in LAI significantly between 1999 and 2000 . Almost all others increased in LAI, but these increases could not be discerned from measurement precision. Precision was determined to be affected more by differences due to measurement time of day than by anniversary date. LAI change over this oneyear period was related to plot damage as measured in 1998 and, to a lesser extent to the amount of understory present. This might indicate that observed changes are partly due to flushing of the understory in damaged plots where light penetration to the forest floor has increased (as observed visually in the field), although this cannot be confirmed until the second ground vegetation survey is completed in 2001. LAI change was not found to be related to treatment (fertilizer, lime or herbicide). A longer period may be required to observe real changes due to treatment.

In this study, widely spaced blocks and unpredictable local cloud formation over the large study area resulted in significant variability in measurement dates of LAI in successive years. Thus, a similar approach to the precision analysis was taken that emulated this variability, leading to a wide confidence interval and a conservative estimate of the number of plots that had changed significantly between 1999 and 2000 . TRAC LAI measurement precision may be improved in studies where it is feasible to measure at consistent times of day and dates (either calendar- or phenologically based) and where plots are more closely spaced. This could provide better capability to statistically discern more subtle temporal differences between years.

\section{Acknowledgements}

We thank Cathy Nielsen, Geoff McVey, John Winters, Peter Neave, Dave Bland, Trudy Vaittinen, Mark Sunohara, Chris Butson and Sylvain LeBlanc for their help during this study and three reviewers for comments on an earlier draft of the paper. Funding for this project has been provided under the Canada - Ontario Agreement for the Ice Storm Economic Recovery Assistance Program, Annex A, Assistance for the Agricultural Sector and Rural Communities in Eastern Ontario. This program is jointly funded by the Government of Canada and the Government of Ontario. Additional funding was provided by the National Science and Engineering Research Council of Canada (NSERC).

\section{References}

Canfield, R. 1941. Application of the line intercept method for sampling vegetation. Journal of Forestry 39: 388-394.

Chen, J.M. and T.A. Black. 1992. Defining leaf area index for nonflat leaves. Plant Cell Environment 15: 421-429.

Chen, J.M. and J. Cihlar. 1995. Plant canopy gap-size analysis theory for improving optical measurements of leaf-area index. Applied Optics 34(27): 6211-6222.

Chen, J.M. 1996. Optically-based methods for measuring seasonal variation in leaf area index of boreal conifer forests. Agricultural and Forest Meteorology 80: 135-163.

Chen, J.M., P.M. Rich, T.S. Gower, J.M. Norman and S. Plummer. 1997a. Leaf area index of boreal forests: theory, techniques and measurements. Journal of Geophysical Research 102 (D24): 29, 429-29, 444.

Chen, J.M., P.D. Blanken, T.A. Black, M. Guilbeault and S. Chen. 1997b. Radiation regime and canopy architecture in a boreal aspen forest. Agricultural and Forest Meteorology 86: 107-125. Environment Canada. 1998. Ice storm 98. http://www.tor.ec. gc.ca/events/icestorm98/icestorm98_the_worst_e.html

Hauer, R.J., M.C. Hruska and J.O. Dawson. 1994. Trees and ice storms: the development of ice storm resistant urban tree populations. University of New Hampshire Cooperative Extension, University of New Hampshire, US Department of Agriculture. http://ceinfo.unh.edu/ icestorm.htm

Irland, L.C. 1998. Ice storm 1998 and the forests of the northeast: A preliminary assessment. Journal of Forestry 96(9): 32-40.

Lautenschlager, R.A. and C. Nielsen. 1999. Ontario's forest science efforts following the 1998 ice storm. The Forestry Chronicle 75(4): 633-641.

Lautenschlager, R.A. and J.A. Winters. 2001. Quantifying ice damage by counting branches on damaged sugar maple trees. The Forestry Chronicle 77(4): 637-642.

Li-Cor. 1991. LAI-2000 PCA Operating Manual. Li-Cor, Inc., Lincoln, Nebraska.

Mageau, M.T., R. Costanza and R.E. Ulanowicz. 1995. The development and initial testing of a quantitative assessment of ecosystem health. Ecosystem Health 1(4): 201-213.

Norman, J.M. 1993. Chapter 4, Scaling processes between leaf and canopy levels. In J.R. Ehleringer and C.B. Field (eds.). Scaling Physiological Processes: Leaf to Globe. Academic Press, Inc., San Diego, California. 388 p.

Olthof, I. and D.J. King. 2000. Development of a forest health index using multispectral airborne digital frame camera imagery. Canadian Journal of Remote Sensing 26(3): 166-176.

Pellika, P., E.D. Seed and D.J. King. 2000. Modelling deciduous forest ice storm damage using aerial CIR imagery and hemispheric photography. Canadian Journal of Remote Sensing 26(5): 394-405. Sampson, P.H., G. H. Mohammed, P.J. Zarco-Tejada, J.R. Miller, T.L. Noland, D. Irving, P.M. Treitz, S.J. Colombo and J. Freemantle. 2000. The Bioindicators of Forest Condition Project: A physiological, remote sensing approach. The Forestry Chronicle 76(6): 941-951. 
Sipe, T.W. and F.A. Bazzaz. 1994. Gap partitioning among maples (Acer) in central New England: shoot architecture and photosynthesis. Ecology 75(8): 2318-2332.

Snedecor, G.W. and W.G. Cochran. 1980. Statistical methods, seventh edition. The Iowa State University Press, Ames. 507 p.

Stevens, J. M. 1992. Applied multivariate statistics for the social sciences, $2^{\text {nd }}$ edition. Lawrence Erlbaum Associates, New Jersey. 629 p.

Ter-Mikaelian, M.T., R.G. Wagner, F.W. Bell and C. Shropshire. 1999. Comparison of photosynthetically active radiation and cover estimation for measuring the effects of interspecific competition on jack pine seedlings. Canadian Journal of Forest Research 29(7): 883-889.
Ter-Mikaelian, M.T. and R.A. Lautenschlager. 2001. Predictive equations for leaf area and biomass for sugar bushes in Eastern Ontario. The Forestry Chronicle 77(4): 643-649.

Van Dyke, O. 1999. A literature review of ice storm impacts on forests in Eastern North America. OMNR, SCSS Technical Report \#112.

Welles, J.M. 1990. Some indirect methods of estimating canopy structure. Remote Sensing Review 5: 31-43.

Welles, J.M. and J.M. Norman. 1991. Instrument for indirect measurement of canopy architecture. Agronomy Journal 83: 818-825. Welles, J.M. and S. Cohen. 1996. Canopy structure measurement by gap fraction analysis using commercial instrumentation. Journal of Experimental Botany 47(302): 1335-1342. 